\title{
Comportamento de cultivares de cebola (Allium cepa L.), caracterizado para dias curtos, em Manaus, AM (1)
}

\author{
Waldelice Oliveira de Paiva $\left({ }^{2}\right)$
}

\begin{abstract}
Resumo
Estudo sobre o comportamento ae cultivares de cebola (Allium cepa L.) de dias curtos, em dois anos agrícolas, em Manaus-AM. Entre os caracteres avaliados, a sobrevivência pús-transplante e plantas improdutivas influenciaram de forma negativa, e em maior intensidade, para a produção das cultivares. Estes caracteres parecem ser críticos para a adaptação da cebola. As cultivares Barreiro Roxa de Piracicaba, Roxa Chata e Baia do Cedo podem contribuir para a obtenção de matərial adaptado às condições de Manaus.
\end{abstract}

\section{INTRODUÇÃO}

A região Amazônica, dadas as suas peculiaridades climáticas, não favorece a adaptação de cultivares de ceboia (Allium cepa L.). Poucos estudos foram efetuados sobre o comportamento e viabilidade agronômica para sua implantação nesta região. Durante muito tempo, o cultivo da cebola esteve concentrado em regiões com estações climáticas mais definidas, onde o verão é caracterizado po f fotoperíodos longos com 13 a 16 horas de luz, dada principalmente a carência de cultivares mais adaptados a fotoperíodos curtos, encontrados nas regiões mais ao norte do Brasil. Sabe-se que o fotoperíodo tem influência marcante na bulbificação da cebola e para cada cultivar existe um fotoperíodo crítico abaixo do qual não há estímulo para a formação de bulbos. $A$ temperatura elevada, quando o fotoperíodo não é limitente, provoca a bulbificação precoce em inúmeros cultivares, e é característica indesejável para a produção comercial (Thomp. son \& Smith, 1938).

A introdução da cebola no vale do submédio São Francisco, na região Nordeste do Brasil, seguida de um eficiente trabalho de seleção e melhoramento, contribuiu para a forma- ção de novos cultivares perfeitamente adaptáveis a esta região, hoje destaque na produção de cebola, que abastece o mercado durante o período de entressafra das regiões Centro e Sul do Brasil (Wanderley et al., 1972, Melo, 1978 e Menezes, 1980). Enquanto que na região Norte, os resultados não foram muito animadores, sendo a cultivar Baia Periforme seriamente atacada por doenças fúngicas. As plantas tarnbém não apresentaram o característico tombamento na época da colheita trazendo problemas na conservação dos bulbos (Pimentel, 1972).

A formação de cultivares caracterizadas para dias curtos, estudados por Paiva (1980), ampliam as possibilidades de que possam ser encontrados cultivares com potencial adaptativo às condições tropicais. O objetivo deste trabalho é avaliar as chances reais do cultivo da cebola, bem como delimitar as cultivares com potencialidade para serem incluídas em um programa de seleção e melhoramento, visando à adaptação desta espécie no Município de Manaus.

\section{MATERIAL E MÉTODOS}

Os experimentos foram conduzidos nos anos agrícolas de 1980 e 1981, em área do campo experimental de olericultura do INPA, situado no Km 14 da Rodovia AM-010, Município de Manaus, em solo arenoso e de baixa fertilidade. O delineamento experimental foi o de blocos ao acaso, com parcelas de $2,00 \mathrm{~m}^{2}$ e de 40 plantas, espaçadas de $0,25 \times 0,20 \mathrm{~m}$, constando de quatro repetições no primeiro ensaio. A adubação básica aplicada foi a equivalente a 0,$4 ; 1,6 ; 2,0 \mathrm{t} / \mathrm{h}$ de uréia, superfosfato triplo e cloreto de potássio, e a acidez

(1) - Trabalho integrante do Projeto financiado pelo POLAMAZÔNIA/CNPq.

(2) - Instituto Nacional de Pesquisas da Amazônia, Manaus. 
corrigida por adição de 3,5 t/ha de calcário dolomítico. A semeadura foi feita na segunda quinzena de julho, transplantando-se as mudas após 60 dias e a colheita dos bulbos finalizada em dezembro de $1980\left(^{(3)}\right.$.

O segundo ensaio efetuado no período de setembro de 1980 a fevereiro de $1981^{*}$ utilizou a mesma adubação do primeiro, diferindo somente na adubação nitrogenada onde foram testados dois níveis $(1,2$ e $0,8 \mathrm{t} / \mathrm{ha})$ com quatro repetições para cada nível. Somente foi parcelada a adubação nitrogenado aplicada na época do transplante, aos trinta e sessenta dias.

O sistema de irrigação utilizado foi por infiltração, e os tratos fitossanitários foram efetuados com intervalos semanais. Foram avaliados os seguintes cultivares de cebola de dias curtos, nos dois experimentos:

\section{Cultivar}

Pira Tropical A/C

Ensaio Utilizado

Barreiro Roxa de Piracicaba

Piranã C.77.27 A/C

II

I,II

Pira Lopes

II

Pira Ouro

II

Pira Grana C. 77.23

I

Pira Dura $\mathrm{A} / \mathrm{C}$

I,II

Roxa Chata

1

I

Baia do Cedo

O comportamento de cada cultivar foi avaliado mediante observações dos seguintes caracteres:

a) sobrevivência pós-transplante: representado pelo número de plantas sobreviventes antes da colheita e expresso em porcentagem para uma população ideal de 40 plantas;

b) plantas improdutivas: expresso pelo número de plantas que não formaram bulbos até à colheita e que foram eliminadas. Este caráter foi expresso em porcentagem em relação ao total de 40 plantas da oarcela;

c) bulbos pequenos categoria 3 (C.3): representados pelo número de bulbos pesando entre 0 e $20 \mathrm{~g}$;

d) bulbos médios categoria 2(C.2): representados pelo número de bulbos pesando entre 21 a $40 \mathrm{~g}$;

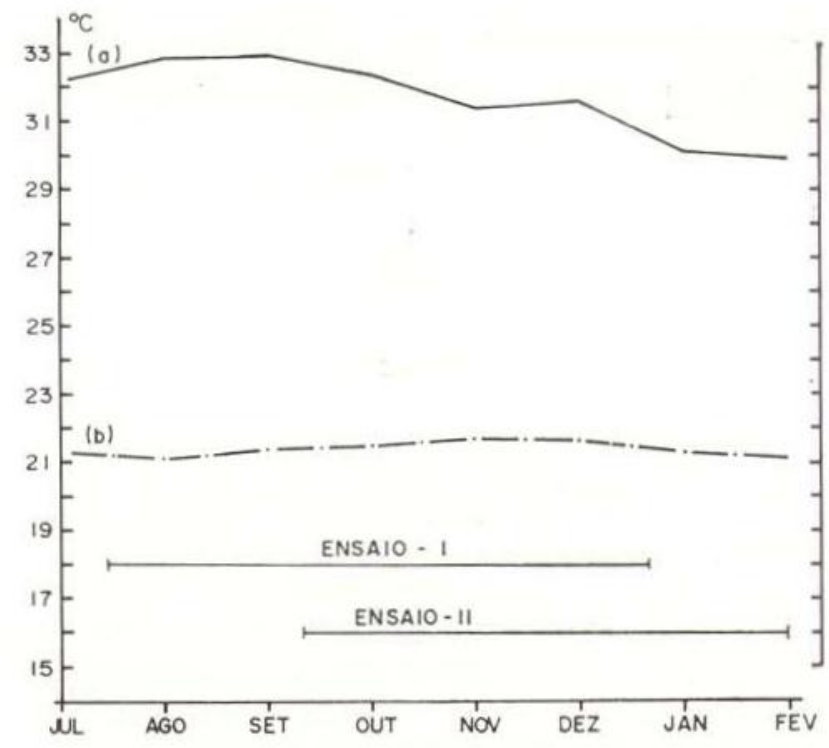

Fig. 1 - Médias mensais das temperaturas máximas (a) e mínimas (b) durante a condução dos ensaios. ReServa Florestal Ducke $-\mathrm{Km} 28$ da Rodovia AM-010.

e) bulbos grandes categoria 1(C.1): número de buibos pesando acima de $40 \mathrm{~g}$;

f) produção total: representado pelo peso total (em gramas) de bulbos produzidos na parcela.

Os dados foram analisados estatisticamente, seguindo metodologia de Pimentel Gomes (1980). Antes da análise, foram efetuadas as transformações para $\sqrt{x+0,5}$ no caso de dados de contagem e logx nos valores apresentados em porcentagem. Para os Valores de Porcentagem de $0 \%$, adotou-se o critério sugerido por Bartlett (1947), ajustando para $1 / 4 n$, sendo $n$ igual ao número total de plantas da parcela. Os dados expressos em porcentagem foram codificados, multiplicando-os pelo valor 1000 , em seguida transformados para logx.

\section{RESUltados E Discussão}

As análises de variância para o Experimento I detectou reação diferencial significativa entre as cultivares para o caráter número de bulbos nas categorias 1 e 3 (Tabela 1). 0 teste de médias, observado na Tabela 2 , indi-

(3) - Os dados metereológicos observados nos períodos referentes aos ensaios constam na Figura 1. 
ca que para a categoria 1 , representado por bulbos com peso superior a $40 \mathrm{~g}$, o melhor comportamento foi para a cultivar Baia do $\mathrm{Ce}$ do. Esta cultivar é originária da população Baia Periforme Lacides e foi obtida através de seleção massal para adaptaçãn às condições de cultivo de verão. Este fato tálvez explique sua capacidade de produzir bu!bos com maiores pesos. Dias \& Costa (1968) relatam também que a Baia do Cedo caracteriza-se por não apresentar bulbificação precoce na fase juvenil, porém em nossas condições esta cultivar mostrou um comportamento adverso, com plantas produzindo bulbos precocemente.

A.s análises de variância dos demais caracteres não apresentaram diferenças significativas porém a cultivar Baia do Cedo pelo seu excelente desempenho quanto à sobrevivência das plantas no campo sobressai-se das demais. Este caráter é deveras importante para a adaptação dos cultivares em nossa região, levando-se em conta que a maior resistência das plantas às doenças, e a não bulbificação precoce das plantas, propiciam a ocorrência de maior número de plantas sobrevi- ventes. Estes fatores são relevartes e não devem ser esquecidos em programas de melhoramento de cebola para as condições tropicais.

A cultivar Roxa Chata, apesar de possuir maior porcentagem de plantas improdutivas e menores valores de número de bulbos da categoria 1 (C.1) apresentou a melhor produção, indicando ser a cultivar que produziu os bulbos de maior peso individual, porém com pesos muito inferiores aos obtidos por Pimentel (1972) para o cultivar Baia Periforme, onde se observou a produção de bulbos com peso médio de até $200 \mathrm{~g}$.

No Experimento II, onde foram utilizados dois niveis de adubação, observa-se na tabela 3 , que a análise de variância não cletectou diferenças significativas para tratamento nos caracteres, número de bulbos categorias 1 e 2 (C.1 e C.2). O desdobramento dos efeitos de tratamentos para os caracteres plantas sobreviventes e produção total foi significativo para a adubação nitrogenada, e no caráter plantas improdutivas os efeitos de cultivares e adubação nitrogenada mostrarom diferenças significantes. Para número de bulbos catego-

TABELA 1 - Valores e significância dos quadracios médios das análises de variância para os caracteres: plantas sobreviventes (P.S), plantas improdutivas (P.!), número de bulbos classificados em três categorias de peso (N.B) e produção total (P.T), em cebola. Experimento I. Manaus (AM) 1980.

Quadrados Mécíios

\begin{tabular}{|c|c|c|c|c|c|c|c|}
\hline \multirow[t]{2}{*}{ Causa da Variação } & \multirow[t]{2}{*}{ GI } & \multirow[t]{2}{*}{ P.S } & \multirow[t]{2}{*}{ P.I } & \multicolumn{3}{|c|}{ N.B (categorias) } & \multirow[t]{2}{*}{ P.T } \\
\hline & & & & C.1 & C.2 & C. 3 & \\
\hline Blocos & 4 & 0,034 & 0,808 & 0,357 & 0,761 & 1,310 & 9938,108 \\
\hline Cultivares & 5 & 0,029 & 0,942 & $0,966^{\circ}$ & 0,510 & $2,739^{*}$ & 9576,448 \\
\hline Erro & 11 & 0,338 & 0,424 & 0,281 & 0,296 & 0,399 & $6.510,667$ \\
\hline $\bar{x}$ & & 3,147 & 4,073 & 1,741 & 3,154 & 7,098 & 140,18 \\
\hline $\mathrm{CV} \%$ & & 33,26 & 15,99 & 40,11 & 30,65 & 23.71 & 57,56 \\
\hline Unidade & & $\log x$ & logy & $\sqrt{w+0,5}$ & $\sqrt{z+0,5}$ & $\sqrt{\Delta+0,5}$ & $g / 2 m^{2}$ \\
\hline & & $\begin{array}{c}\mathrm{x}: \% \text { de } \\
\text { Plantas }\end{array}$ & $\begin{array}{l}\text { y: } \% \text { de } \\
\text { Plantas }\end{array}$ & $\begin{array}{c}\text { w: } n .^{\circ} \text { de } \\
\text { bulbos } \\
(>40 \mathrm{~g})\end{array}$ & $\begin{array}{l}z:{ }^{\circ} \text { de } \\
\text { bulbos } \\
(20-40 \mathrm{~g})\end{array}$ & $\begin{array}{c}\Delta: n^{\circ} \text { de } \\
\text { bulbos } \\
(<20 \mathrm{~g})\end{array}$ & \\
\hline
\end{tabular}

C.1: "Categoria 1; bulbos com peso médio superior a $40 \mathrm{~g}$.

C. 2: Categoria 2; bulbos com peso médio variando entre 20 a 40 g

C. 3: Categoria 3; bulbos com peso médio inferior a $20 \mathrm{~g}$.

- : Significativo a $5 \%$ de probabilidade pelo teste $\mathrm{F}$. 
TABELA 2 - Média dos Caracteres: plantas sobreviventes, plantas improdutivas, número médio de bulbos em três categorias de peso e produção total, em cebola. Experimento I. Manaus (AM). 1980 ".

\begin{tabular}{|c|c|c|c|c|c|c|}
\hline \multirow{3}{*}{ Cultivares } & \multicolumn{5}{|c|}{ Caracteres } & \multirow{3}{*}{ P.T } \\
\hline & \multirow[t]{2}{*}{ P.S } & \multirow[t]{2}{*}{ P.I } & \multicolumn{3}{|c|}{ N.B (categorias) } & \\
\hline & & & C.1 & C.2 & C.3 & \\
\hline Barreiro Roxa de Piracicaba & 56,250 & 11,875 & $4,25 \mathrm{bc}^{*}$ & 1,5 & $2,00 \mathrm{ab}$ & 139,05 \\
\hline Pira Lopes & 50,625 & 18,125 & 7,75 abc & 4,25 & $1,25 a b$ & 77,48 \\
\hline Baia P. Piracicaba & 48,750 & 19,375 & $9,25 a b$ & 3,00 & $0,25 \mathrm{~b}$ & 130,68 \\
\hline Pira Grana & 54,375 & 8,750 & 10,5 a & 3,25 & $0,75 a b$ & 66,15 \\
\hline Roxa Chata & 65,625 & 55,625 & $1,0 \mathrm{c}$ & 1,75 & $1,00 \mathrm{ab}$ & 209,3 \\
\hline Baia do Cedo & 73,125 & 11,875 & 11,75 a & 4,5 & 4,75 a & 198,2 \\
\hline DMS $5 \%$ & n.s & n.s & 1,453 & n.s & 1,218 & n.s \\
\hline
\end{tabular}

C.1: Categoria 1; bulbos com peso médio superior a $40 \mathrm{~g}$.

C. 2: Categoria 2; bulbos com peso médio variando entre 20 a $40 \mathrm{~g}$.

C. 3: Categoria 3 ; bulbos com peso médio inferior a $20 \mathrm{~g}$.

- Médias dentro da coluna seguidas pela mesma letra nöo diferem significativamente pelo teste de Tukey, ao nível de $5 \%$ de probabilidade.

n.s. : Nỗo significativo.

ria 3 (C.3), houve significância somente para cultivares, mostrando que as cultivares reagem diferentemente à bulbificação precoce.

$\mathrm{Na}$ avaliação das médias pelo teste de Tukey (Tabela 4), o caráter número de plantas sobreviventes, no nível de adubação $A$ (adição de 1, 2 ton/ha de uréia), apenas Pira Grana diferiu das demais com os menores valores e Barreiro Roxa de Piracicaba desponta como a melhor. Igual comportamento observa-se também no nível de adubação $B$ (adição de 0.8 ton/ha de uréia). A cultivar Barreiro Roxa de Piracicaba segundo Silva (1976), apresenta resistência ao Mal de Sete Voltas, causado pelo fungo Colletotrichum gloeosporioides Penz (Sensu Arx, 1957). Provavelmente, esta deve ser a causa do maior número de plantas sobreviventes, pois apesar dos tratos fitossanitários constantes, as demais cultivares foram seriamente atacados por inúmeras doenças foliares.

O caráter número de plantas improdutivas apresentou maior valor para Barreiro Roxa de Piracicaba nos dois níveis de adubação e os menores valores ficaram com Piranã e Pira Lopes, respectivamente no nível A e B. Supõe-se que a cultivar Barreiro Roxa de Piracicaba, em relação às demais cultivares, seja a mais afe- tada pela adubação nitrogenada necessitando para bulbificar, de uma maior permanência no campo, pois as plantas de cebola, segundo Sculy et al., (1945) quando submetidas a foto. períodos críticos, o excesso de nitrogênio tem o poder de alongar o ciclo, provocando, com isso, uma colheita tardia. Tal fato não pode ser observado neste trabalho dada a colheita dos bulbos ter sido efetuada em uma mesma época para todos os cultivares. 0 melhor comportamento das cultivares Piranã e Pira Lopes, em relação ao caráter número de plantas improdutivas, pode ser explicado por serem estas cultivares de maturação precoce, sendo que, na época de coiheita as plantas já se apresentavam bulbificadas.

$\mathrm{Na}$ avaliação do caráter número de bulbos, categorias 1 e 2 (C.1 e C.2), apesar de não ter havido diferenças significativas, observa-se que a bulbificação foi precária e que de 40 plantas iniciais, houve a formação de, no máximo, três bulbos acima de $20 \mathrm{~g}$ por parcela. Nota-se que o efeito da temperatura elevada acelerou a bulbificação, produzindo um maior número de bulbos pequenos, confirmando os estudos de Thompson \& Smith (1938), que demonstraram o efeito de temperaturas acima de $26^{\circ}$ em acelerar a bulbificação e pro- 
duzir bulbos muito pequenos. Para diminuir os efeitos da bulbificação precoce sugere-se que, nos ensaios posteriores, a adubação nitrogenada seja efetuada em parcelas mais frecüentes alongando-se o ciclo vegetativo das plantas antes de iniciar a bulbificação.

A produção total de bulbos por parcela, no nível $A$, mostrou Pira Tropical e Baia do Cedo como as cultivares mais produtivas, e no nível B, Pira Tropital e Barreiro Roxa de Piracicaba foram as melhores. A adubação nitrogenada, como já foi citado anteriormente, também influenciou na produção de bulbos apresentando a melhor produção total somente nas parcelas em que foram adicionadas 0,8 t/ha de uréia (nível B).

Comparando-se os dados contidos nas tabelas 2 e 4 , observa-se que as cultivares Barreiro Roxa de Piracicaba e Baia do Cedo podem ser consideradas como as mais estáveis, pois não sofreram tanta influência das condi- ções ambientais ocorridas na época dos doịs ensaios. Estas cultivares também, junto com a cultivar Roxa Chata apresentaram o melhor desenvolvimento vegetativo. Todas as cultivares, se bem que em diferentes graus, foram seriamente prejudicadas pelo ataque de Alternaria porii e Colletotrichum dematium $\left({ }^{4}\right)$ independente da época do experimento. Os resu! tados encontrados sugerem que as cultivares acima citadas poderão ser de grande valia para iniciar um programa de seleção e melhoramento para cebola adaptada às condições tropicais. Novos ensaios serão efetuados para confirmar esta suposição, pois os dados contidos neste trabalho são avaliações preliminares de uma cultura de reações pouco conhecidas em nossa região.

Os coeficientes de variação nos dois experimentos estão com valores baixos para a maioria dos caracteres, demonstrando que os ensaios foram efetuados com boa precisão.

TABELA 3 - Valores e significância dos Quadrados Médios das Análises de Variância para os caracteres: plantas sobreviventes (P.S), plantas improdutivas P.I), número de bulbos (N.B) em três categorias de peso e produção total (P.T), em dois níveis de adubação, em cebola. Experimento II. Manaus (AM) 1981.

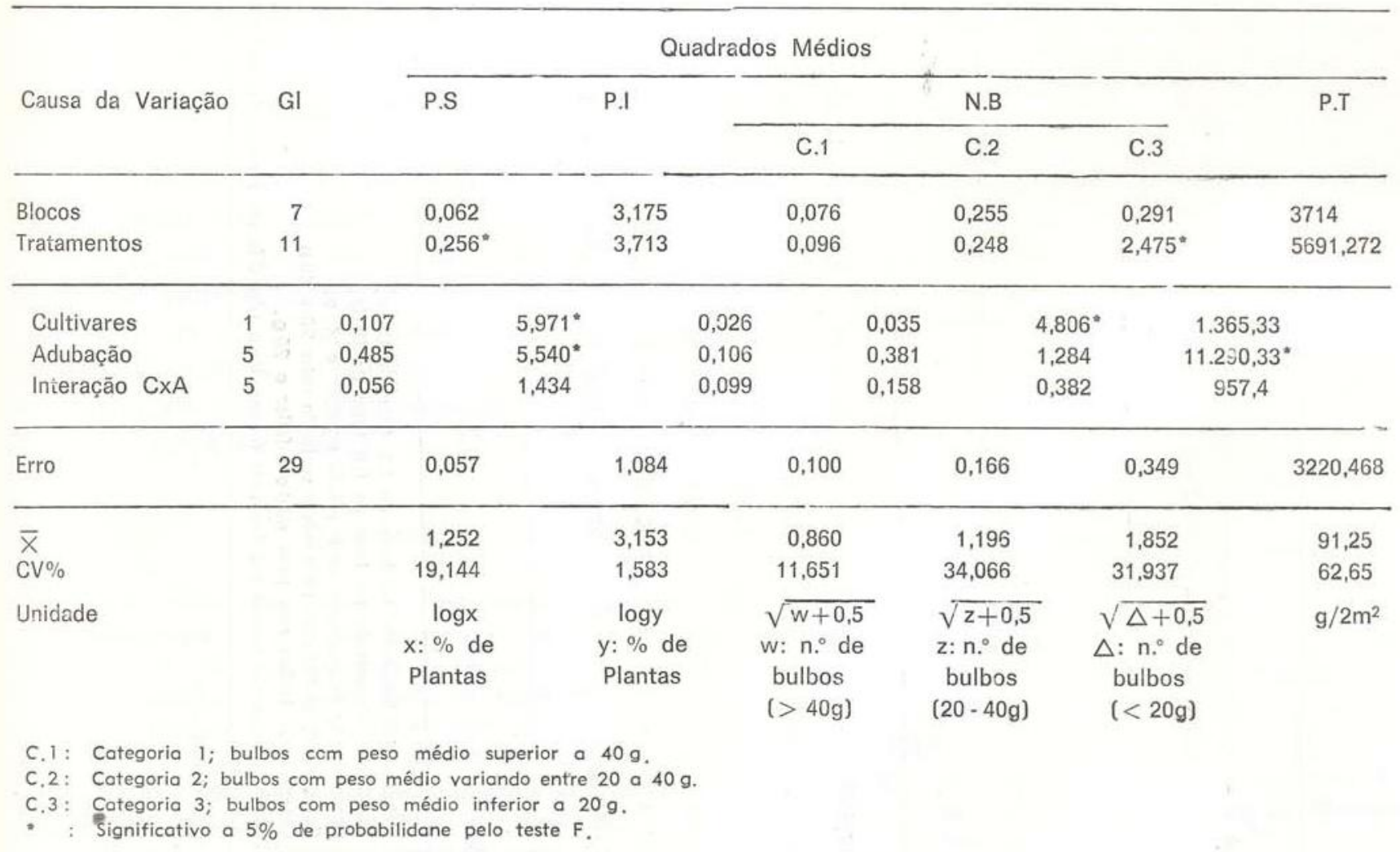

(4) - Identificados pela Dra. Maria Luiza Braz Alves, Divisão de Fitossanidade/INPA/CNPq. 
TABELA "4 - Média dos Caracteres: plantas scbreviventes (P.S), plantas improdutivas (P.I), número de bulbos (N.B) em três categorias de peso e produção total (P.T), em dois níveis de adu'ação, em cebola. Experimento II. Manaus (AM) 1981.

\begin{tabular}{|c|c|c|c|c|c|c|c|c|c|c|c|c|}
\hline \multirow{3}{*}{ Cultivares } & \multirow{2}{*}{\multicolumn{2}{|c|}{ P.S }} & \multirow{2}{*}{\multicolumn{2}{|c|}{ P.I }} & \multicolumn{6}{|c|}{ N.B. } & \multirow{2}{*}{\multicolumn{2}{|c|}{ P.T }} \\
\hline & & & & & \multicolumn{2}{|c|}{ C.1 } & \multicolumn{2}{|c|}{ C.2 } & \multicolumn{2}{|c|}{ C. 3} & & \\
\hline & $A^{\prime}$ & $\mathrm{B}^{2}$ & A & B & A & B & A & B & A & B & A & B \\
\hline Pira Tropical & $14,4 \mathrm{a}$ & $18,13 \mathrm{bc}^{*}$ & $9,4 \mathrm{a}$ & $8,1 \mathrm{ab}$ & 1,0 & 2,0 & 1,0 & 2,0 & $1,0 \mathrm{bc}$ & $2,0 \mathrm{~b}$ & 112,0 & 163,8 \\
\hline Barreiro Roxa de Piracicaba & $30,0 \mathrm{a}$ & 58,2 a & $25,0 \mathrm{a}$ & $43,8 \mathrm{a}$ & 1,0 & 1,0 & 2,0 & 3,0 & $1,0 \mathrm{bc}$ & $1,0 \mathrm{~b}$ & 100,5 & 114,3 \\
\hline Piranã & $12,5 \mathrm{a}$ & $11,9 \mathrm{~cd}$ & $3,1 \mathrm{a}$ & $5,6 \mathrm{bc}$ & 0,0 & 1,0 & 1,0 & 1,0 & $3,0 \mathrm{ab}$ & $1,0 \mathrm{~b}$ & 32,5 & 42,5 \\
\hline Pira Lopes & 29,4 a & $28,2 a b$ & $8,0 \mathrm{a}$ & $3,1 \mathrm{c}$ & 0,0 & 1,0 & 2,0 & 1,0 & $7,0 \mathrm{a}$ & $10,0 \mathrm{a}$ & 103,8 & 102,3 \\
\hline Pira Grana & $8,1 \mathrm{~b}$ & $11,0 \mathrm{~d}$ & $3,8 \mathrm{a}$ & $0,6 \mathrm{c}$ & 1,0 & 0,0 & 1,0 & 1,0 & $2,0 \mathrm{bc}$ & $4,0 \mathrm{a}$ & 52,8 & 54,5 \\
\hline Baia do Cedo & 27,5 a & $26,9 \mathrm{~b}$ & $6,9 \mathrm{a}$ & $1,9 \mathrm{c}$ & 1,0 & 0,0 & 2,0 & 1,0 & $7,0 \mathrm{a}$ & $11,0 \mathrm{a}$ & 110,3 & 98,3 \\
\hline DMS $5 \%$ & & & & & & & & & & & & \\
\hline
\end{tabular}

(1) Adubação nitrogenada na base de 1,2 t/ha de Uréia.

2) Adubaçấo nitrogenada na base de 0,8 t/ha de Uréia.

C.1: Cotegoria 1; bulbos com peso médio superior a $40 \mathrm{~g}$.

C.2: Categoria 2; bulbos com peso médio variando entre 20 a $40 \mathrm{~g}$

C. 3: Categoria 3; bulbos com peso médio inferior a $20 \mathrm{~g}$.

- : Médias dentro da coluna seguida pela mesma letra nốo diferem significativamente pelo teste de Tukey, ao nivel de $5 \%$ de probabilidade.

n.s. : Não significativo, 
Entretanto, o coeficiente de variação para produção total por parcela mostra-se elevado, fato este que pode ser explicado face a producão ser a somatória de todos os componentes analisados, os quais quando avaliados em conjunto variaram bastante.

\section{CONCLUSÕES}

Houve comportamento diferencial das cultivares relacionados aos caracteres em avaliação;

Nas condições do segundo ensaio, a adı. ção de 1,2 t/ha de uréia alongou o ciclo vegetativo de algumas cultivares, retardando a bulbificação e conseqüentemente prejudicando a produção final;

Plantas sobreviventes e plantas improdutivas foram os caracteres mais influenciados, tanto pela adubação nitrogenada como pelas condições climáticas de nossa região;

As cultivares Baia do Cedo, Roxa Chata e Barreiro Roxa de Piracicaba podem contribuir para obtenção de genótipos adaptados às condições de Manaus.

\section{Agradecimentos}

Ao Dr. Cyro P. da Costa pelo envio das cultivares aqui testadas bem como as sugestões e orientação em nosso trabalho; à Dra. $M^{a}$ de Nazaré Goes por nos antecipar gentilmente os informes metereológicos e à Srta. Lenita Jacob de Oliveira, estudante de Agronomia da ESALQ/USP, pela sua contribuição nas coletas dos dados.

\section{SUMMARY}

A study was made of the behavior of onion (Allium cepa L.) cultivars, with short day characters, during two agricultural years in Manaus, AM. Among the characters evaluated those of transplant survival and unproductive plants influenced negatively the production of the cultivars. It was concluded that these characters are critical for the adaptation of the onion, and the cultivars Barreiro Roxa de Piracicaba, Roxa Chata and Baia do Cedo can contribute genetic variability in different degrees, to obtain onions adapted to the condictions of Manaus.

\section{REFERENCAIS BIBLIOGRÁFICAS}

BARTLETT, M.S.

1947 - The use of transformation. Biometrics. Washington, 3: 39-52.

DIAS, M. \& COSTA, C.P.

968 - Seleção para a cultura do cedo na variedade brasileira de cebola Baia Periforme precoce. Relatório Científico do Instituto de Genética. ESALQ/USP, Piracicaba, SP. 125-130.

MELO, P.C.T.

1978 - Seleção massal estratificada em duas populações de cebola (Allium cepa L.) Baia Periforme no Vale do sub-médio São Francisco. Piracicaba, ESALQ/USP, 72p. (Dissertação de Mestrado).

MENEZES, D.

1980 - Seleção de Populações de Cebola (Allium cepa L.) do Grupo Baia Periforme para épocas de cultivo no Vale do sub-médio São Francisco. Piracicaba, ESALQ/USP, 102p. (Dissertação de Mestrado).

PAIVA, W.O.

1980 - Comportamento de novas cultivares de cebola (Allium cepa L.) no sistema de cultivo de bulbinho de inverno em relação aos cultivos tradicionais. Piracicaba. ESALQ/ USP, 70p. (Dissertação de Mestrado).

PIMENTEL, A.A.M.P.

1972 - Observações Preliminares sobre possibilidades do cultivo de (Allium cepa L.) na região de Belém-Pará. Revista de Olericultura. Vol. XII. Fortaleza, 77.

PIMENTEL GOMES, F.

1978 - Curso de Estatística Experimental. São Paulo. 8. ed. $430 \mathrm{p}$.

SCULLY, N.J.; PARKER, N.W.; BORTHWICK, H.A.

1945 - Interation of nitrogen nutrition and photoperiod expressed in bulbing and flower stalk development of onion. Botanical Gazette, Chicago, 107: 52-61.

SILVA, N.

1976 - Resistência em cebola (Allium cepa L.) à colletotrichum gloeosporioides Penz (SENSO ARX, 1957). Piracicaba, ESALQ/USP. 67p. (Dissertação de Mestrado).

THOMPSON, H.C. \& SMITH, O.

1938 - Seedstalk and bulb development in the onion, (Allium cepa L.), Bulletim of Cornell Agricultural Experimental Station. Geneva. (708): 1-21.

WANDERLEY, L.J.G.; QUEIROZ, M.A.; WANDERLEI, M.B. 1972 - Competição de variedades de cebola (Allium cepa L.). Revista Brasileira de Olericultura, Fortaleza, 12 (67).

(Aceito para publicação em 10/09/81) 